\title{
Detection of Reinforcement Corrosion in Reinforced Concrete Structures by Potential Mapping: Theory and Practice
}

\author{
Gino Ebell $(\mathbb{D}$, Andreas Burkert, and Jürgen Mietz \\ Federal Institute for Materials Research and Testing (BAM), Berlin, Germany \\ Correspondence should be addressed to Gino Ebell; gino.ebell@bam.de
}

Received 5 August 2018; Accepted 5 September 2018; Published 30 September 2018

Guest Editor: Tao Cheng

Copyright ( 2018 Gino Ebell et al. This is an open access article distributed under the Creative Commons Attribution License, which permits unrestricted use, distribution, and reproduction in any medium, provided the original work is properly cited.

\begin{abstract}
Electrochemical potential mapping according to guideline B3 of DGZfP (German Society for Nondestructive Testing) is a recognized technique for the localization of corroding reinforcing steels. In reinforced concrete structures the measured potentials are not necessarily directly linked to the corrosion likelihood of the reinforcing steel. The measured values may be significantly affected, different from, e.g., stress measurement, by different influences on the potential formation at the phase boundary metal/concrete itself as well as the acquisition procedure. Due to the complexity of influencing factors there is a risk that the results are misinterpreted. Therefore, in a training concept firstly the theoretical basics of the test method should be imparted. Then, frequently occurring practical situations of various influencing factors will be made accessible to the participants by a model object specially designed for this purpose. The aim is to impart profound knowledge concerning the characteristics of potential mapping for detecting corrosion of reinforcing steel in order to apply this technique in practice as reliable and economical test method.
\end{abstract}

\section{Introduction}

In steel reinforced or prestressed concrete structures corrosion attack is generally impossible due to the high alkalinity of concrete environments. The reason for this protection is a passive layer on the steel surface which provides adequate corrosion resistance. The long-term durability of this protection against corrosion is connected with the stability of conditions necessary for the passive layer. Depending on concrete quality and constructional characteristics under certain environmental conditions the passivation effect of the concrete pore solution can be neutralized (carbonation, chloride ingress) leading to depassivation of the reinforcement surface. As a result corrosion reactions of the steel may occur. Due to the volume expansion of the generated iron oxide reaction products cracks or spalling of the concrete cover may develop.

In order to plan and perform necessary rehabilitation measures, early and mainly nondestructively determined information about the actual corrosion behavior of the steel reinforcement is of utmost importance. The potential mapping technique is an established and common method to assess the corrosion state of reinforcing steel in reinforced concrete structures [1-5]. Areas of active corroding reinforcement can be nondestructively localized. This method is usually applied for the detection of chloride-induced corrosion.

\section{Measuring Technique}

During the potential mapping of reinforced concrete structures the potential difference between the reinforcing steel embedded in concrete and an external reference electrode placed on the concrete surface is determined (Figure 1). As the reinforcement has to be locally contacted the method is quasi nondestructive.

The potential differences are obtained on a previously defined measuring grid. Different reference electrode types are available depending on the measurement task. Rod electrodes can be used for spot or individual measurements, while wheel-electrode systems are usually used for larger areas.

Figure 2 shows the so-called potential funnel which can be detected only in a 3D representation. Locally limited and pronounced potential shifts to more negative potential values 


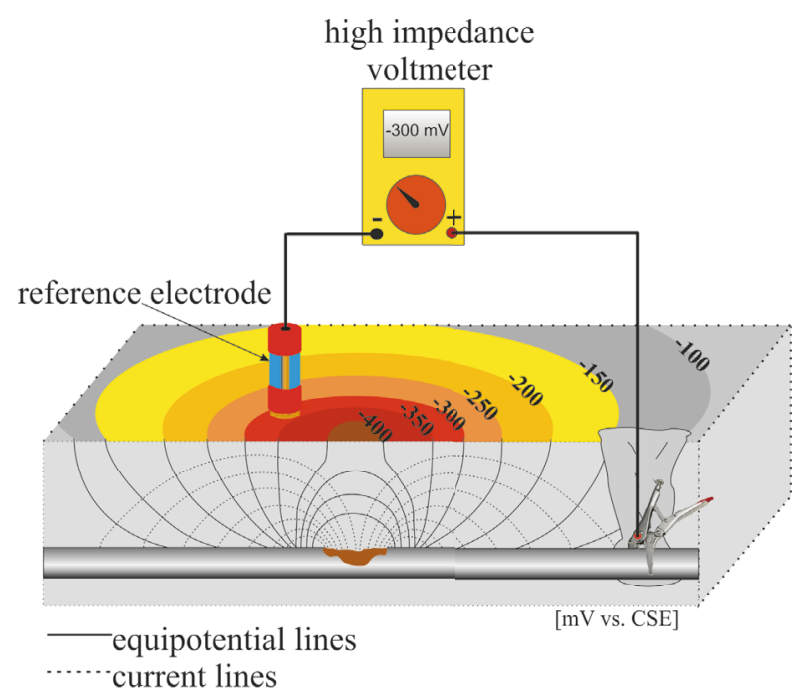

FIGURE 1: Principle of potential mapping.

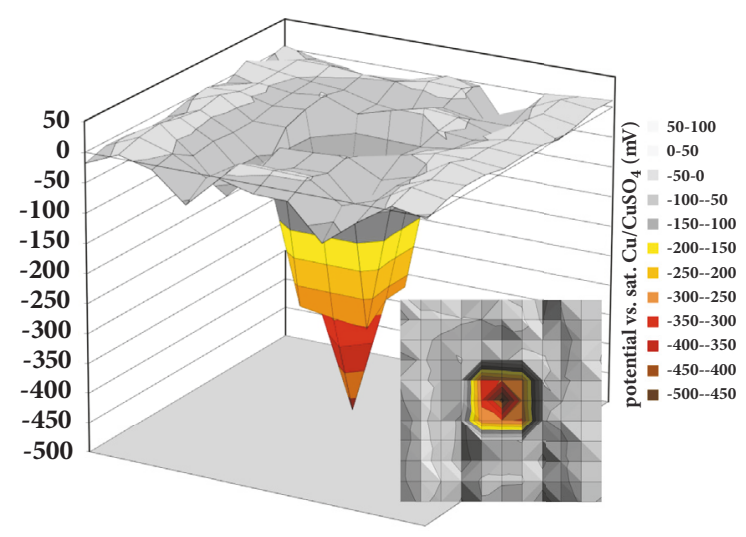

Figure 2: 3D representation of a potential funnel.

are often an indication of active reinforcement corrosion. The absolute potential values are of minor importance. According to $[1,3]$ the main focus is the detection of potential gradients forming such potential funnels. Contrary to this, in ASTM Standard C876 [4], the corrosion probability is designated to fixed potential values. The evaluation of potential mapping data only according to the threshold values given in [4] is not recommended as there is no direct correlation of corrosion probability and measured potential without considering the population.

The performing of the measurement and the requirements for the test personnel are described in detail in the DGZfP Specification B03 [1] and the SIA Guideline 2006 [3].

\section{Evaluation and Interpretation}

3.1. Additional Investigations. The interpretation of the potential mapping regarding the condition of corrosion of the steel reinforcement requires additional investigations taking into account possible influencing factors like varying concrete moisture or concrete cover.
The following additional requirements are indispensable for a reliable assessment of a potential mapping:

complete measurement of the concrete cover

checking the concrete surface for hollow locations/ delaminations

complete investigation of the concrete surface regarding
exposed reinforcement
remnants of sealing
frost damage, concrete damage, and crack for- mations
drainage installations

sampling of bore dust samples to determine chloride profiles

random determination of carbonation depth

opening and assessment of the reinforcement at conspicuous areas

Optional additional investigations are, e.g.,

(i) determination of the electrolytic resistance of concrete

(ii) measuring concrete moisture by means of microwaves

3.2. Graphical Representation. The graphical representation of the measuring results should always be made with suitable boundary parameters which should enable a clear and effective visualization of the probability of reinforcement corrosion.

Figure 3 shows as an example a colour representation with a zoning of $50 \mathrm{mV}$ for each assigned colour. In this case the dark red and dark orange colour indicate areas with high corrosion probability (potentials between -300 and $-500 \mathrm{mV}$ versus copper/copper-sulfate electrode).

For the graphical representation of potential mapping data the signal effect of the colours used should be regarded. In the given example (Figure 3 ) the most negative potential values (and hence the most critical ones) are represented by red and brown colours. The choice of other colours should consider that they provide a clear allocation between colour and probability of corrosion. Areas of high and low corrosion probability should be easily distinguished.

The statistical analysis (frequency distribution or cumulative frequency distribution) of potential values for the definition of potential limit values for the assignment of corrosive and noncorrosive areas requires a high level of expertise. Different moisture conditions in concrete can lead to a shift in the potential level by more than $100 \mathrm{mV}$ leading to misinterpretations in the statistical analysis.

\section{Final Appraisal and Random Opening}

After graphical evaluation of the potential mapping data a random opening of the concrete cover to inspect the 


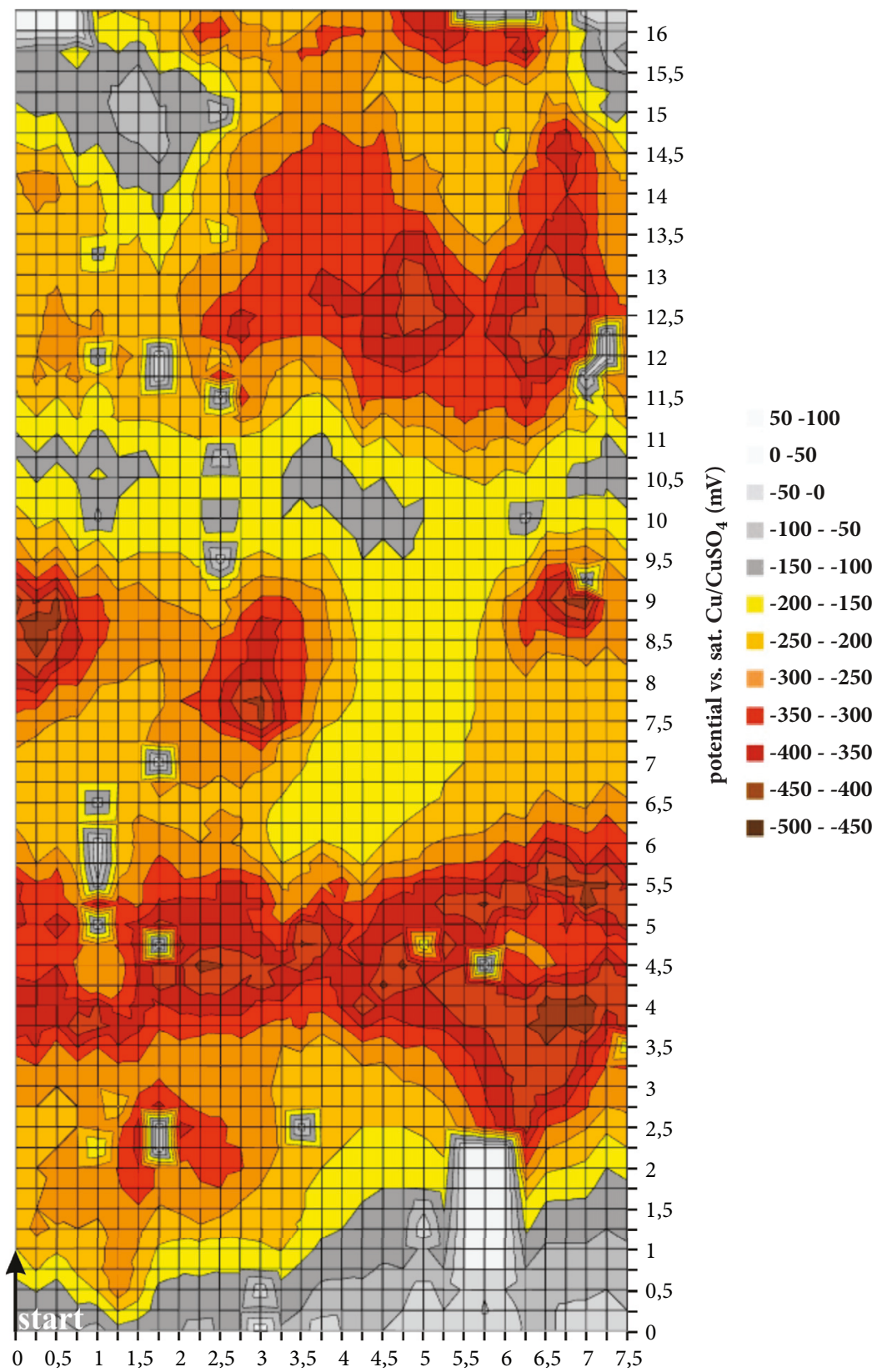

FIGURE 3: Graphical representation of measured potential field of a concrete slab.

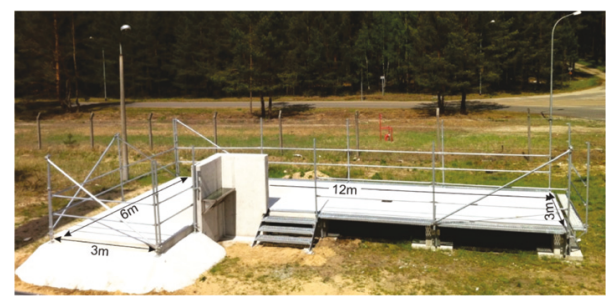

Figure 4: Large-scale test specimen of BAM, Berlin.

reinforcement locally with respect to the actual degree of damage has to be performed. This should be done in areas with the most negative potentials. Also in areas with cracks or unclear potential distribution, local areas have to be opened and the reinforcement condition inspected. This procedure has to be conducted for each measuring surface. General conclusions from one measuring area to the whole structure are not possible. Only after validation of the measuring data with the corresponding local inspections a final assessment of the rehabilitation requirements can be made.

\section{Test Personnel}

Due to the high requirements for the test personnel the qualification is outlined in the DGZfP specification B03 as follows [1]: the process of potential mapping and the interpretation of the measurement results require sufficient expertise in the 


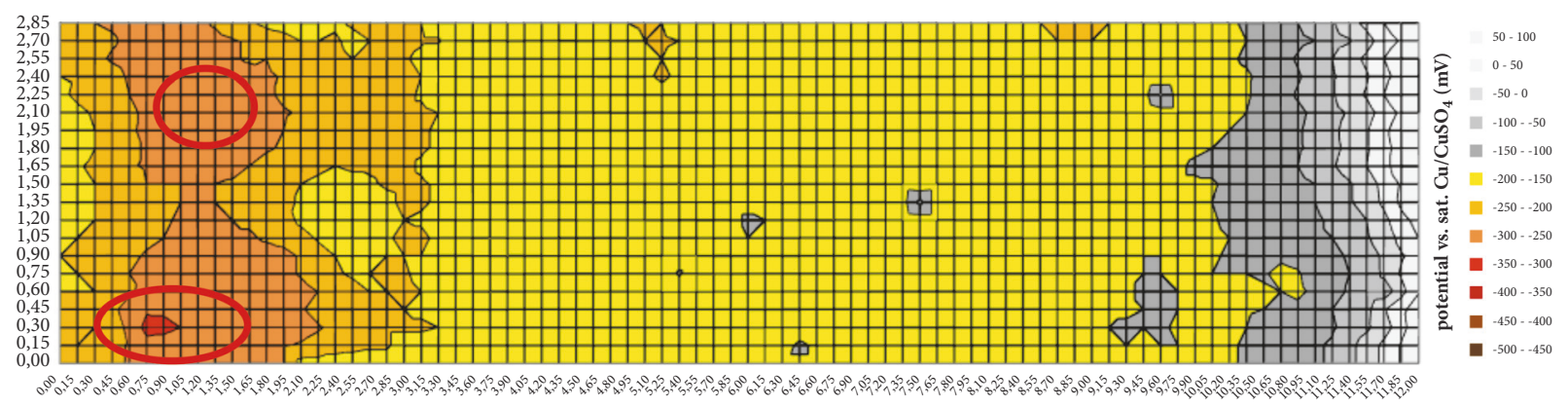

FIgURE 5: Potential mapping results of the large-scale specimen-two anodes.
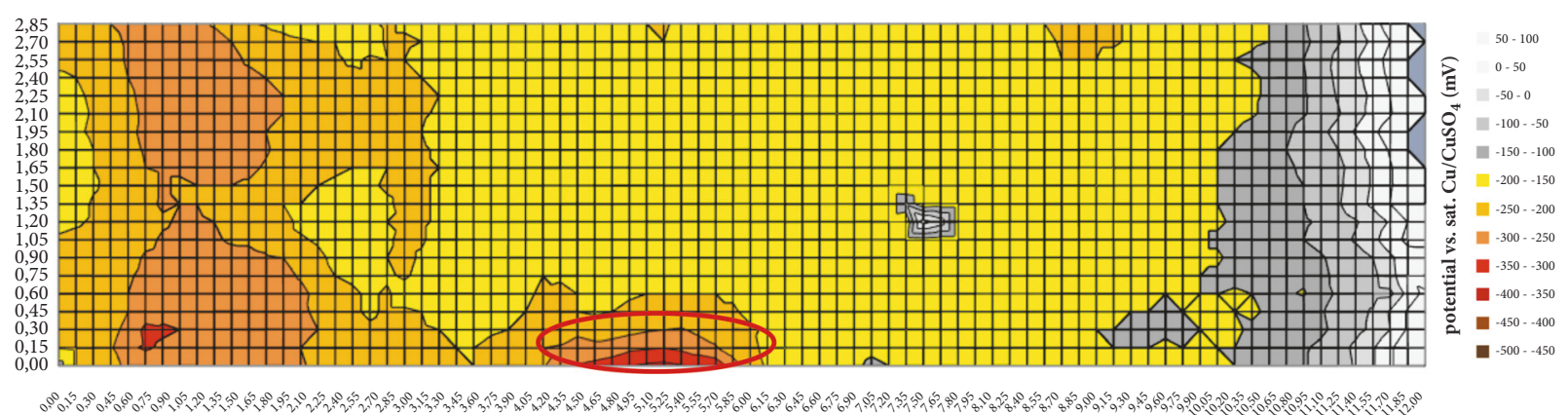

FIgURE 6: Potential mapping results of the large-scale specimen—two anodes and the galvanized stairway.

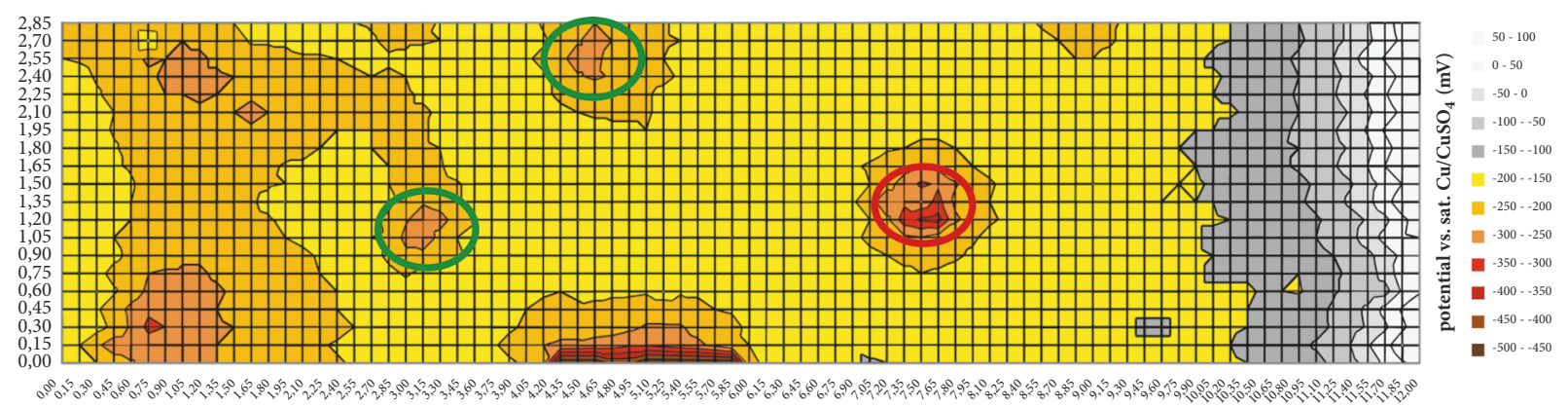

Figure 7: Potential mapping results of the large-scale specimen—four anodes, the galvanized stairway, and the connected floor drain.

area of both corrosion and corrosion protection, as well as concrete technology and at least basic knowledge in the field of structural engineering. The proof of this expertise may be given, e.g., via certifications or proof of formal qualifications of appropriate advanced training. The measurements themselves can also be conducted by test personnel without background knowledge in electrochemistry, if under the guidance of a responsible skilled inspector. In this case, the measurement collection process must be controlled by the inspector.

\section{Results of the Practical Training Courses at the Large-Scale Test Specimen}

Training courses for the acquisition of the proof of expertise for performing potential mapping measurements are carried out at three locations in Germany (Aachen, Berlin, and München). The course is subdivided into a theoretical and a practical training and lasts for 3 days including theoretical and practical examinations. The practical training takes place at a large-size test specimen including hidden corroding reinforcement as well as practice-relevant sources of error. Figure 4 shows the test specimen of the Federal Institute of Research and Testing (BAM), Berlin.

The specimen was constructed in 2011, the used concrete is based on a CEM III blast furnace slag cement mixture with a water/cement ratio of 0.45 and a maximum grain size of 16 $\mathrm{mm}$. The lower and upper reinforcement-layer are electrically insulated by special constructed spacers. Different anodic areas as well as $\mathrm{MnO}_{2}$ reference electrodes are embedded in the specimen. Additionally, influencing components like a galvanized stairway and a metallic floor drain are also integrated. They can be connected or disconnected to the reinforcement by a switch-control-center. In Figures 5-9 the measuring grid is always 15 by $15 \mathrm{~cm}$; the used reference electrode was a saturated copper copper-sulfate electrode (sat. $\mathrm{Cu} / \mathrm{CuSO}_{4}$ ). 


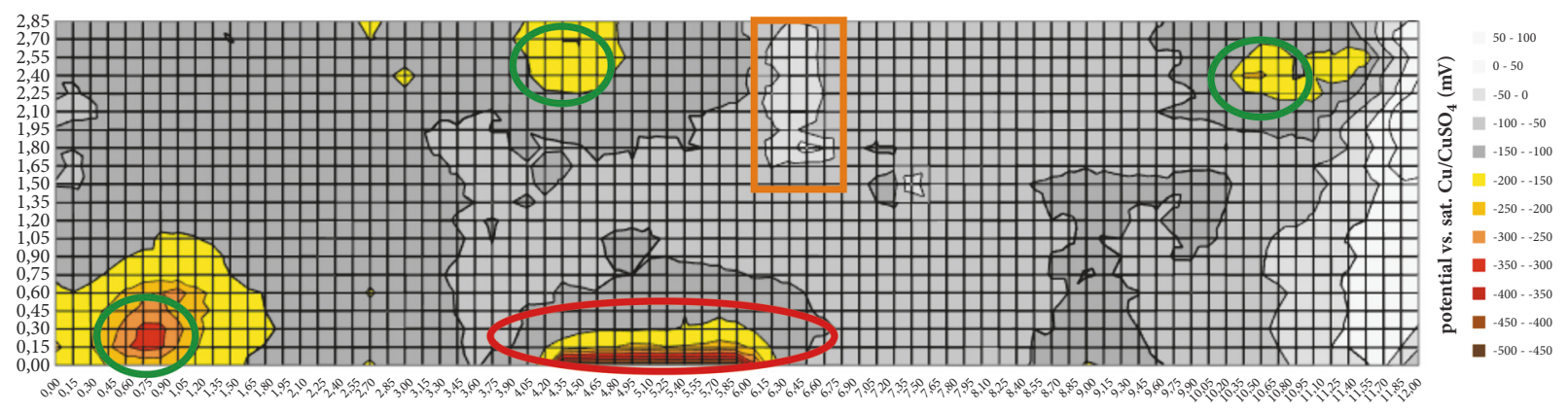

Figure 8: Potential mapping results of the large-scale specimen—three anodes, the galvanized stairway, and an epoxy coated area.

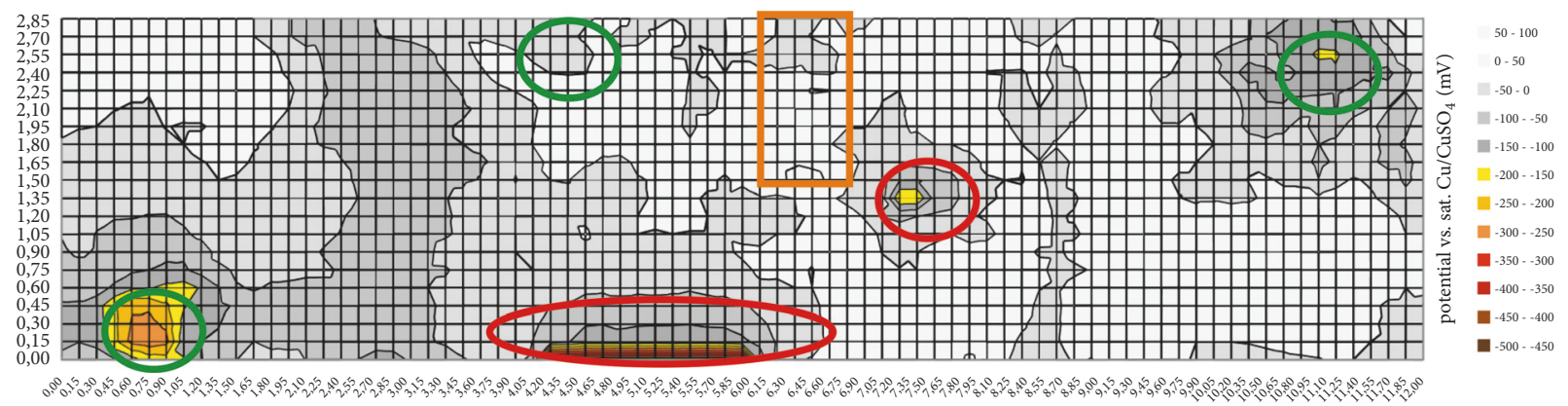

FIGURE 9: Potential mapping results of the large-scale specimen at a nonmoistened surface-three anodes, the galvanized stairway, connected floor drain, and an epoxy coated area.

At this test specimen as well as similar specimens in Aachen (ibac) and Munich (cbm) the training for measuring potentials, concrete cover, electric resistance of concrete, and other necessary measurements is carried out. Figure 5 shows one of the first results of the measurement-campaign from spring 2012 (specimen age 7 months). The potential measurement starts 30 minutes after moistening the concrete surface. During the measurement the concrete surface has to be moistened without any ponding. Two of the embedded anodes are connected (marked with red colour) none of the influencing metallic parts is connected.

Figure 6 shows results of a potential mapping from the same measurement-campaign as in Figure 5, in this case with two connected anodes (see Figure 5) and the galvanized stairway (marked with red colour).

Figure 7 shows similar results like Figure 6 but with a connected floor drain (marked with red colour) and two further anodes (marked with green colour).

Figure 8 shows a result of a measurement-campaign from 2017 (6-year-old specimen). In this measurement-campaign three anodes (marked with green colour) and the galvanized stairway (marked with red colour) are connected. In the year 2016 an epoxy based coating was partially applied (marked with orange colour). The influence of the coating is clearly visible by more positive potentials against the surrounding area. Furthermore, the potential of the passive reinforcement is about 50 to $100 \mathrm{mV}$ more positive than 5 years before.

Figure 9 shows similar results like Figure 8, the main difference is the nonmoistened surface and the connected floor drain (smaller red marker) in case of Figure 9. The electrolytical connection between the wheel-electrode and the concrete surface was carried out by moistening the spongeband of the wheel-electrode. The measured potentials are more positive and the anodic areas are smaller, which is based on the higher electrolytic resistivity of the concrete. Just two of the three anodes are visible in case of the dry surface (green marked). The influence of the epoxy coated area is not visible.

Figures 5-9 clearly demonstrate the complex interrelations; the differences between the measured potentials from 2012 and 2017 are especially enormous. The measured potentials are not comparable-just the potential differences between anodic and cathodic areas are comparable. Based on these results it becomes clear that potential mapping results should be interpreted by the potential differences, so-called potential funnels, and not by measured absolute potential. Influences of metallic building parts like the galvanized stairway, when they are electrically connected to the embedded reinforcement, can be misinterpreted as an anodic area. In case of an electrically connected floor drain the interpretation of the measured potentials can be a bit more difficult. The negative potentials are definitely based on an active corroding system but it is difficult to distinguish between corroding floor drain or reinforcement in the surrounding area.

\section{Conclusions}

Years of experience with potential mapping have shown that clients often order potential mapping without considering 
the qualification of the test personnel. In a lot of cases they only get potential values without any interpretation and without information about boundary conditions regarding influencing factors. Rehabilitation measures are based on such measurements. And without knowing and considering the complex correlations between the different factors it can happen that areas will be rehabilitated without any real need to do so or-what is worse-that areas will not be rehabilitated although there is severe corrosion of the reinforcement.

Without any proof of sufficient expertise, the planning and assessment of potential mapping measurements could lead to serious misinterpretations and should be avoided.

\section{Data Availability}

The data used to support the findings of this study are included within the article.

\section{Conflicts of Interest}

The authors declare that they have no conflicts of interest.

\section{References}

[1] DGfZP: Specification B 03, Electrochemical Half-Cell Potential Measurements for the Detection of Reinforcement Corrosion, DGZfP, Berlin, Germany, 2014.

[2] S. Kessler, C. Gehlen, G. Ebell, and A. Burkert, "Potential mapping and its probability of detection," Beton- und Stahlbetonbau, vol. 106, no. 7, pp. 481-489, 2011.

[3] SIA and Merkblatt, Planung, Durchführung und Interpretation der Potenzialmessung an Stahlbetonbauten, Schweizerische Ingenieur- und Architektenverein, 2013.

[4] ASTM, C 876-15 Standard Test Method for Corrosion Potentials of Uncoated Reinforcing Steel in Concrete, ASTM, 2015.

[5] B. Elsener, C. Andrade, J. Gulikers, R. Polder, and M. Raupach, "RILEM TC 154 EMC: Electrochemical Techniques for Measuring Metallic CorrosionHalf cell potential measurements Potential mapping on reinforced concrete structures," Materials and Structures, vol. 36, pp. 461-471, 2003. 


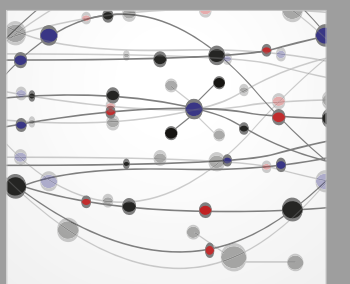

The Scientific World Journal
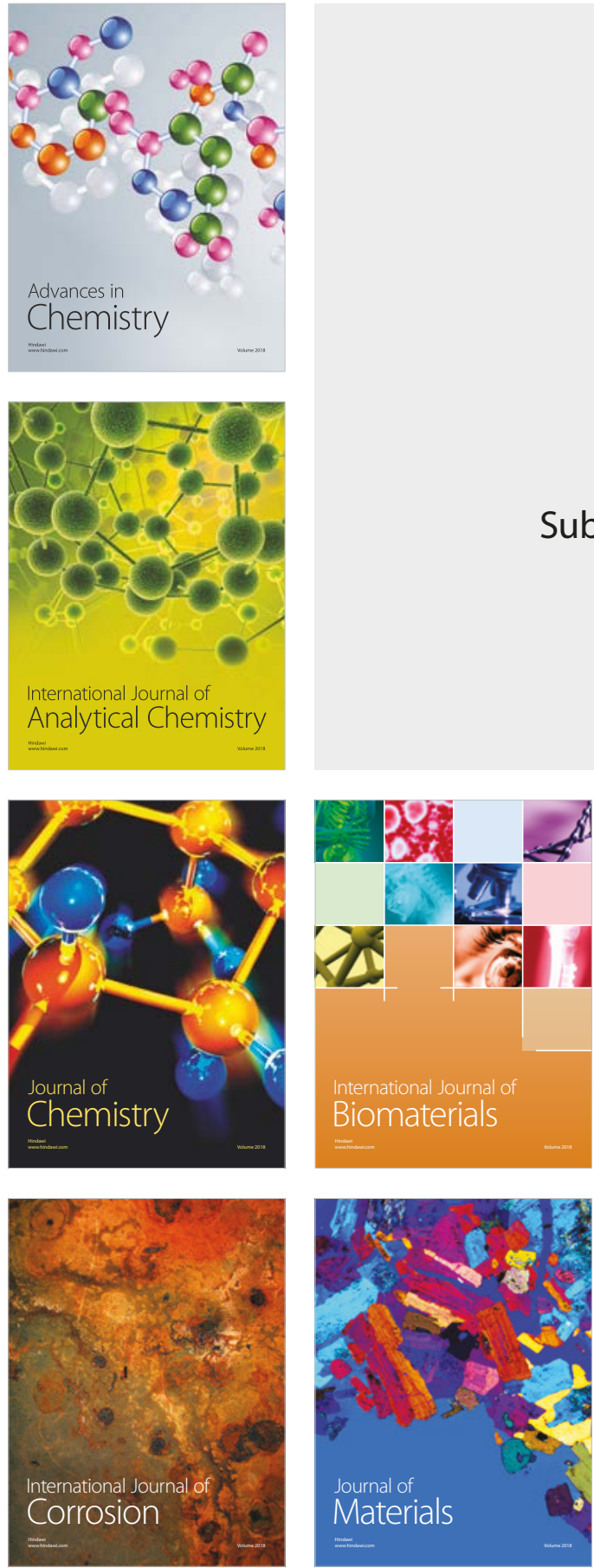

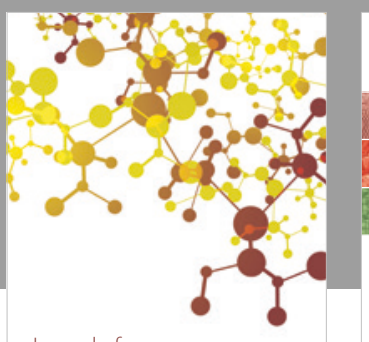

Journal of

Applied Chemistry
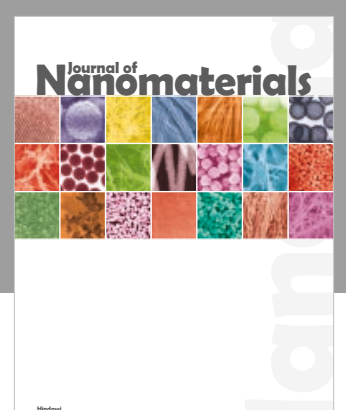

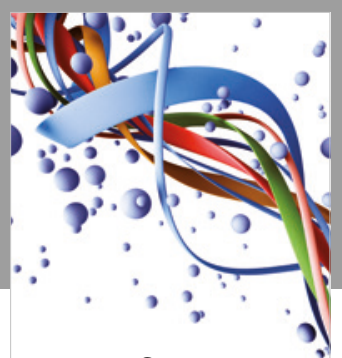

Scientifica

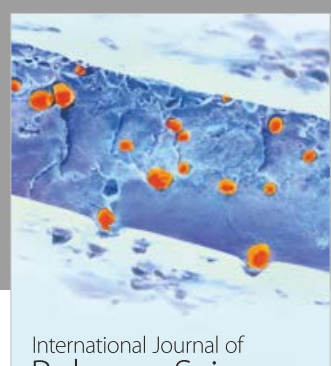

Polymer Science

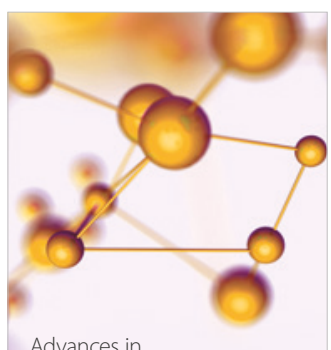

Physical Chemistry
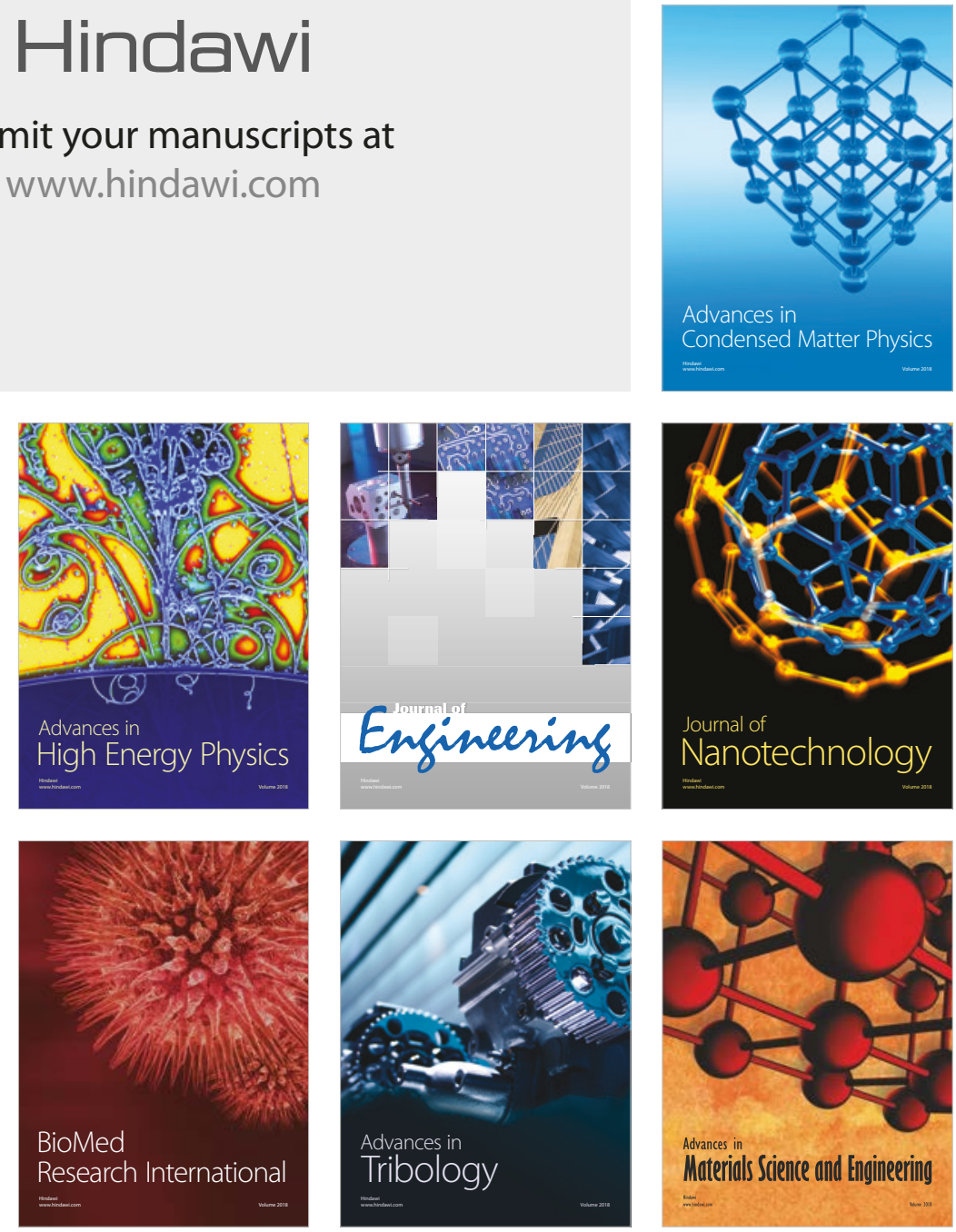